\title{
HIỆU QUẢ CỦA MÔ HÌNH HỌC TẬP KHÁM PHÁ TRONG DAYY HỌC CÁC MÔN ĐÀO TẠO NGHỀ SU' PHẠM ĐÁP Ú'NG CHUẨN ĐẦU RA Ở TRƯỜNG ĐẠI HỌC NGOẠI NGŨ̉ - ĐẠI HỌC QUỐC GIA HÀ NỘI
}

\author{
Nguyễn Thị Thắng* \\ Bộ môn Tâm lý - Giáo dục, Truờng Đại học Ngoại ngũu, ĐHQGHN, \\ Phạm Văn Đồng, Cầu Giấy, Hà Nội, Việt Nam \\ Nhận bài ngày 12 tháng 06 năm 2017 \\ Chỉnh sửa ngày 01 tháng 07 năm 2017; Chấp nhận đăng ngày 29 tháng 09 năm 2017
}

\begin{abstract}
Tóm tắt: Trên cơ sở khái quát một số vấn đề cơ bản về học tập khám phá, nghiên cứu tập trung phác họa hiệu quả học tập mà sinh viên đạt được qua mô hình học tập khám phá và qua các phương pháp học tập truyền thống môn Giáo dục học - một môn đào tạo nghề sư phạm ở Trường Đại học Ngoại ngữ - Đại học Quốc gia Hà Nội. Với các phương pháp nghiên cứu định tính và định lượng, trong đó có 02 phương pháp chính là thực nghiệm sư phạm và điều tra bằng phiếu hỏi, nghiên cứu đã cho thấy học tập khám phá hiệu quả hơn và vượt trội hơn các phương pháp, mô hình học tập truyền thống khác trong giảng dạy các môn đào tạo nghề sư phạm, thể hiện ở: hứng thú học tập môn học; khả năng độc lập và lưu giữ kiến thức của người học; tính tự tin và tự chủ trong học tập của người học; kiến thức môn học, các kỹ năng nghề nghiệp và kỹ năng hành động của người học; môi Trường học tập tích cực của người học; cũng như thời gian đầu tư cho học tập môn học và sự đánh giá kết quả học tập của sinh viên bằng điểm số. Từ kết quả nghiên cứu này, giảng viên được khuyến nghị nên vận dụng mô hình học tập khám phá thường xuyên trong dạy học các môn nghiệp vụ sư phạm nói riêng, các môn học nói chung ở bậc đại học.
\end{abstract}

Tư khóa: học tập khám phá, dạy học, phương pháp dạy học, hiệu quả, môn nghiệp vụ sư phạm

\section{1. Đặt vấn đề}

Đào tạo nhân lực đáp ứng chuẩn đầu ra trong một xã hội bùng nổ thông tin, bùng nổ tri thức là một yêu cầu tất yếu đặt ra với các Trường đại học $(\mathrm{ÐH})$, cao đẳng $(\mathrm{CĐ})$ nói chung, Trường Đại học Ngoại ngữ - Đại học Quốc gia Hà Nội (ĐHNN - ĐHQGHN) nói riêng. Chương trình các môn học hiện nay ở các Trường học được xây dựng theo hướng tích hợp môn học nhằm góp phần đáp ứng yêu cầu đó. Nhưng chúng ta lại không thể tăng thời gian học tập của sinh viên trong mỗi ngày hay kéo dài thời gian học tập ở Trường của sinh viên. Điều quan trọng đối với chúng ta, những người làm công tác giảng dạy và giáo dục là làm thế

\footnotetext{
* ĐT.: 84-936775969

Email: ntthang1010@gmail.com
}

nào để giúp người học có các kỹ năng, có cách tiếp cận, cách xử lý và vận dụng thông tin, tri thức một cách khoa học và hiệu quả, đáp ứng mục tiêu đào tạo đặt ra. Thực tế, giảng viên, giáo viên luôn có nhiều việc phải làm và cần làm như đổi mới nội dung (ND), chương trình, đổi mới phương pháp dạy học (PPDH) và kiểm tra - đánh giá (KT-ĐG) trong dạy học (DH), tự bồi dưỡng và năng cao năng lực chuyên môn, năng lực sư phạm,... Vấn đề đổi mới PPDH và KT-ĐG theo hướng phát triển năng lực cho người học là việc mà giáo viên, giảng viên luôn ý thức được tầm quan trọng, sự cần thiết trong thực tiễn giảng dạy và cũng là vấn đề mà không dễ thực hiện một cách hiệu quả đối với tất cả giảng viên và giáo viên.

Qua thực tế giảng dạy các môn đào tạo nghề sư phạm cho sinh viên Trường ĐHNN 
- ĐHQGHN, chúng tôi nhận thấy có thể vận dụng các phương pháp (PP), mô hình học tập tích cực khác nhau để nâng cao hiệu quả học tập cho sinh viên, đáp ứng mục tiêu đào tạo theo chuẩn đầu ra, ví dụ dạy học góc, học thông qua thực hành dạy học tập khám phá (HTKP),.... Trong đó, mô hình học tập có hiệu quả nổi trội hơn cả các phương pháp khác về khả năng phát huy tính chủ động, sáng tạo của người học; tăng hứng thú học tập và giúp người học phát triển các kỹ năng tư duy, khả năng tự chủ, độc lập trong học tập...và cũng là mô hình học tập được nhiều nhà giáo dục trên thế giới cũng như ở Việt Nam quan tâm nghiên cứu là mô hình học tập khám phá. Mô hình học tập này được nghiên cứu và áp dụng ở các bậc học, môn học khác nhau tại nhiều nước trên thế giới từ khá lâu (đầu thế kỷ 20). Tuy nhiên, đến nay chưa có công trình nào nghiên cứu về mô hình học tập khám phá trong đào tạo, bồi dưỡng giáo viên nói chung, đào tạo, bồi dưỡng giáo viên ngoại ngữ nói riêng ở Việt Nam. Bài báo này là một phần kết quả nghiên cứu ứng dụng mô hình khám phá trong giảng dạy các môn đào tạo nghề sư phạm ở Trường ĐHNN - ĐHQGHN. Bài báo chỉ ra một vài nét cơ bản về mô hình học tập khám phá và hiệu quả của nó trong dạy học các môn nghiệp vụ sư phạm (NVSP) ở Trường ĐHNN - ĐHQGHN.

\section{Câu hỏi và phương pháp nghiên cứu}

\subsection{Câu hỏi nghiên cưu}

Học tập khám phá được nghiên cứu, vận dụng trong dạy học nhiều môn học khác nhau, và cũng đã được áp dụng giảng dạy với nhiều đối tượng người học khác nhau. Các nghiên cứu đã chỉ ra mô hình học tập khám phá đã mang lại những hiệu quả đáng kể trong dạy học các môn học, như toán học, hóa học, sinh học và ngoại ngữ cho học sinh phổ thông. Khi vận dụng mô hình học tập này trong dạy học môn các môn đào tạo nghề sư phạm (Giáo dục học) ở Trường ĐHNN - ĐHQGHN hiệu quả sẽ ra sao? Cụ thể, mô hình học tập này liệu có hiệu quả hơn so với các PPDH truyền thống khác khi được vận dụng trong giảng dạy môn Giáo dục học cho sinh viên ngành sư phạm ngoại ngữ ở Trường ĐHNN - ĐHQGHN. Hiệu quả của mô hình học tập, PPDH được biểu hiện ở các khía cạnh:

- Hứng thú học tập các môn NVSP (đào tạo nghề sư phạm ngoại ngữ)

- Khả năng độc lập và lưu giữ kiến thức của người học

- Tính tự tin và tự chủ trong học tập của người học

- Kiến thức môn học, các kỹ năng nghề nghiệp và kỹ năng hành động của người học

- Môi trường học tập tích cực của người học.

\subsection{Phuoong pháp nghiên cúu}

Trong điều kiện về thời gian, nhân lực và vật lực hiện có của đơn vị phụ trách các môn nghiệp vụ sư phạm ở Trường ĐHNN ĐHQGHN, nghiên cứu tập trung đánh giá hiệu quả của mô hình HTKP trong giảng dạy môn Giáo dục học và nghiên cứu đã sử dụng các phương pháp:

\section{Các phuơng pháp nghiên cứu lý luận}

Nghiên cứu sử dụng các phương pháp phân tích, so sánh, tổng hợp, hệ thống hoá các tài liệu có liên quan nhằm nghiên cứu cơ sở lý luận cho vấn đề nghiên cứu.

\section{Phuoong pháp thực nghiệm su phạm}

Tổ chức dạy học thực nghiệm (TN) các giờ học môn Giáo dục học cho sinh viên năm thứ ba, hệ sư phạm thông qua mô hình học tập khám phá nhằm kiểm nghiệm tính khả thi và hiệu quả của mô hình học tập này trong đào tạo nghề sư phạm ở Trường $\mathrm{DHNN}$ ĐHQGHN.

Thực nghiệm vận dụng mô hình học tập khám phá trong dạy học môn Giáo dục học được tổ chức trên 02 lớp sinh viên năm thứ ba (QH 2014) hệ sư phạm với 115 sinh viên, thời gian từ 9/2016 - 1/2017. Song song với 02 lớp 
dạy thực nghiệm này là 02 lớp đối chứng $(\mathrm{DC})$ với số 89 sinh viên và $\mathrm{PPDH}$ truyền thống (PP thuyết trình, tự đọc sách, tự nghiên cứu,...) được sử dụng thường xuyên trong các giờ học môn Giáo dục học.

\section{Phuoong pháp điều tra bằng phiếu hỏi}

Phương pháp này được sử dụng nhằm khảo sát tình hình và đánh giá hiệu quả sử dụng các $\mathrm{PP}$, mô hình học tập trong quá trình dạy học các môn đào tạo nghề sư phạm ở Trường ĐHNN - ĐHQGHN.

\section{Phuơng pháp quan sát}

Quan sát hoạt động học tập của sinh viên trên lớp và hoạt động của giảng viên để có những đánh giá khách quan nhất về hiệu quả của mô hình học tập khám phá trong dạy học môn Giáo dục học. Phương pháp này hỗ trợ cho phương pháp điều tra.

Phuơng pháp xủ lý số liệu bằng thống kê toán học

Sử dụng phương pháp thống kê toán học để xử lý các dữ liệu, các thông tin trong quá trình nghiên cứu, điều tra, thu thập từ các phương pháp trên. Đây là phương pháp nghiên cứu bổ trợ cho các phương pháp trên.

\section{Thang đánh giá:}

Đánh giá mức độ sử dụng các $\mathrm{PPDH}$, các hình thức học tập khám phá và hiệu quả của mô hình học tập này trong dạy học môn Giáo dục học cho sinh viên năm thứ 3 hệ sư phạm, Trường ĐHNN-ĐHQGHN được đánh giá theo thang điểm Likert:

- Mức độ sử dụng các PPDH; các hình thức học tập khám phá: Thường xuyên: +1 ; Thỉnh thoảng: +2 ; Hiếm khi: +3 ; Chưa bao giờ: +4.

- Đánh giá hiệu quả của mô hình học tập khám phá trong dạy học môn Giáo dục học: Tốt: +1 ; Khá: +2 ; Trung bình: +3 ; Yếu: +4 .

- Ý nghĩa của từng giá trị trung bình đối với thang đo khoảng (Interval Scale)

Giá trị khoảng cách $=$ (Maximum Minimum $) / \mathrm{n}=(4-1) / 4=0.75$

Giá trị trung bình ý nghĩa:
1.00 - 1.75 Thường xuyên/ Tốt

1.76 - 2.50 Thỉnh thoảng/ Khá

2.51 - 3.25 Hiếm khi/ Trung bình

3.26 - 4.00 Chưa bao giờ/ Yếu

\section{Một số vấn đề lý luận}

Học tập khám phá được Jerome Bruner giới thiệu như một lý thuyết học tập chính thức vào năm 1960. Đây là một mô hình dạy học dựa trên sự khám phá của người học. Mô hình này khuyến khích người học tự xây dựng kiến thức mới cho mình dựa trên kinh nghiệm và kiến thức đã có. Thông qua việc sử dụng trực giác, trí tưởng tượng và sự sáng tạo của mình người học tìm kiếm các thông tin mới để khám phá sự thật, tương quan và chân lý mới. Học không bằng cách hấp thụ những gì mình được nghe hoặc đọc, nhưng tích cực tìm kiếm câu trả lời và các giải pháp cho các vấn đề.

Theo Bruner (1960, 1961), với mô hình học tập khám phá:

- Nội dung học tập không phải được truyền tải bởi người dạy mà do người học phát hiện độc lập;

- Người học là người tham gia tích cực và được khuyến khích đặt câu hỏi và tìm câu trả lời;

- Học tập khám phá ở phạm vi rộng hay hẹp đều hướng vào cá nhân người học;

- Học tập khám phá như là một cách để xác định và cung cấp cấu trúc cách thức cá nhân học do đó hoạt động dạy học như một quá trình hướng dẫn cho nghiên cứu giáo dục.

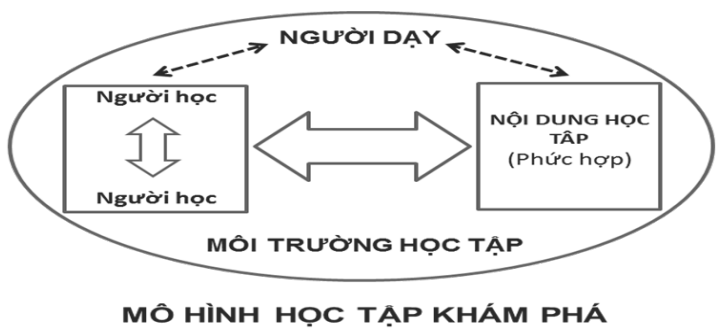

Trong học tập khám phá, người học tích cực, chủ động kiến tạo kiến thức cho bản thân qua kinh nghiệm vốn có và qua tương tác với môi Trường học tập. HTKP không chỉ giúp người học nắm chắc kiến thức, hình thành những kĩ 
năng, kĩ xảo đáp ứng mục tiêu đầu ra mà quan trọng hơn là phát triển được khả năng tư duy sáng tạo của người học và những trải nghiệm trong thực tế giúp người học hoàn thiện bản thân đáp ứng được yêu cầu phát triển của xã hội.

HTKP không chỉ giới hạn những khía cạnh nhận thức của việc dạy và học. Sự học tập hợp tác đòi hỏi và khuyến khích phát triển không chỉ có lý trí mà còn phát triển cả về mặt tình cảm, giao tiếp; mục đích học tập là xây dựng kiến thức của bản thân nên khi đánh giá các kết quả học tập không định hướng theo các sản phẩm học tập, mà cần kiểm tra những tiến bộ trong quá trình học tập và trong những tình huống học tập phức tạp (Nguyễn Phúc Chỉnh \& Nguyễn Thị Hằng, 2010).

\section{Đặc điểm của hoc tập khám phá}

Bicknell-Holmes và Hoffman (2000) mô tả ba thuộc tính chính của việc học phát hiện như: 1) khám phá và giải quyết vấn đề để tạo, tích hợp và khái quát kiến thức, 2) hoạt động dựa trên sở thích của học sinh và 3 ) hoạt động khuyến khích lồng ghép kiến thức mới vào cơ sở kiến thức hiện có của người học.

Theo Svinki (1998), học tập khám phá có ba đặc điểm chính sau đây:

- Hoc tập tích cưc: người học là người tham gia tích cực trong quá trình học tập chứ không phải là một chiếc thuyền rỗng chứa những lời giảng của thầy giáo.

- Hoc tập có ý nghĩa: học tập khám phá có nhiều ý nghĩa vì nó tận dụng sự liên tưởng của bản thân học sinh như là cơ sở của sự hiểu biết.

- Thay đổi niềm tin và thái độ: học tập khám phá đặt nhiều trách nhiệm học tập hơn cho người học, học sinh thường phải vận dụng các quá trình tư duy để giải quyết vấn đề và phát hiện các điều cần học, vì vậy các em phải có nhiều trách nhiệm hơn cho sự học tập của mình.

Uu và nhuợc điểm của học tập khám phá Các tác giả Eskandari \& Soleimani(2016); Mukharomah (2015); Rahmi và Ratmanida (2014); Mirasi, Osodo và Kibirige (2013);
Oghenevwede (2010); Cohen (2008); Rachel (2006); Saab, Van Joolingen \& Hout-Wolters (2005); hay Svinki (1998); Castronova (2002) đều cho rằng học tập khám phá hiệu quả hơn và vượt trội so với các phương pháp học tập khác trong việc giảng dạy sinh học; toán học, ngôn ngữ học và sự vượt trội đó thể hiện ở: kiến thức, kỹ năng học tập; sự cá nhân hoá những kinh nghiệm học tập; hứng thú và động lực học tập; tính tự chủ và khả năng độc lập cững như mức độ lưu giữ kiến thức của người học;...

Tuy nhiên, các tác giả trên cũng cho rằng mô hình học tập khám phá không nên được sử dụng như một phương pháp giảng dạy chính, bởi vì nó có những hạn chế trong thực tế: tốn thời gian, giảng viên cần phải được chuẩn bị nhiều và rất kỹ; dễ dẫn đến sự thất vọng cho người học bởi mô hình học tập này không thể bao quát hết các nội dung của cả khóa học và khó thực hiện ở những lớp đông người học;...

\section{Kết quả nghiên cứu thực tiễn}

\subsection{Một số vấn đề về dạy học môn Giáo duc hoc ở Truòng ĐHNN - ĐHQGHN}

Từ khóa QH 2012, toàn ĐHQGHN, trong đó có Trường ĐHNN, đã tiến hành rà soát, và xây dựng chương trình đạo tạo đáp ứng chuẩn đầu ra. Cùng với nhiều môn học khác trong các chương trình đào tạo của Trường, môn Giáo dục học (GDH) - một trong số các môn NVSP (Tâm lý học, Giáo dục học, QLHCNNQLGD\&ĐT,...) đã được tích hợp từ hai học phần (04 tín chỉ) thành một học phần - 3 tín chỉ. Với 03 tín chỉ môn học được thiết kế thành 07 chuyên đề bao quát toàn bộ những vấn đề cơ bản nhất của Giáo dục học nhằm giúp người học có được kiến thức cơ bản về khoa học giáo dục và hình thành, phát triển ở họ những kỹ năng sư phạm, kỹ năng hành động cũng như những phẩm chất cần thiết của người giáo viên để sinh viên có thể làm chủ và phát triển bản thân trong môi trường toàn cầu hóa mà nền kinh tế dựa vào tri thức là chính. 
Phương pháp giảng dạy và học tập môn học được đổi mới ngay khi thực hiện nội dung, chương trình mới. Mô hình học tập khám phá được sử dụng trong giảng dạy và nhận được những phản hồi tích cực từ sinh viên. Sau mỗi khóa học chúng tôi, đều nhìn nhận, đánh giá những điều giảng viên và sinh viên đạt được và chưa đạt được qua mô hình học tập này. Trên cơ sở đó, chúng tôi có những điều chỉnh về nội dung, kiến thức môn học và đặc biệt là cách thức tổ chức các hình thức học tập khám phá nhằm đáp ứng chuẩn đầu ra của môn học.

Kiểm tra đánh giá môn học cũng được đổi mới để đáp ứng yêu cầu đào tạo theo chuẩn đầu ra. Để hoàn thành môn học, ngoài việc phải đảm bảo số buổi lên lớp, sinh phiên phải hoàn thành 02 bài tập chuyên đề, 01 bài kiểm tra giữ kỳ và 01 bài thi cuối kỳ. Trong đó 02 bài tập chuyên đề và bài kiểm tra chiếm $40 \%$ tổng số điểm môn học, được gọi là điểm quá
4.2. Hiệu quả hoc tập đạt được của sinh viên sau khi kết thúc môn học

- Hiệu quả học tập đạt được của sinh viên qua mô hình họ tập khám phá

Hiệu quả học tập sinh viên đạt được qua mô hình học tập khám phá môn Giáo dục học khá cao, thể hiện ở tất cả 7 khía cạnh, có điểm trung bình dao động $1,66<\overline{\mathbf{X}}<2,3<2,5$ (bảng 1).

Hứng thú học tập của sinh viên thể hiện khá rõ qua các buổi lên lớp học môn Giáo dục họcvới mô hình học tập khám phá. Phần đông sinh viên thấy hứng khởi với mỗi giờ học và họ không bị cảm giác thời gian trôi qua rất chậm. Đặc biệt, mỗi ngày sinh viên cảm nhận được nhiều hơn sự hữu ích và sự hấp dẫn của môn học.

Bảng 1. Hiệu quả đạt được của mô hình học tập khám phá trong dạy học môn Giáo dục học

\begin{tabular}{|c|c|c|c|c|c|c|c|}
\hline \multirow{2}{*}{ STT } & \multirow{2}{*}{$\begin{array}{l}\text { Hiệu quả học tập sinh viên } \\
\text { đạt được sau khi kết thúc } \\
\text { môn học }\end{array}$} & \multicolumn{2}{|c|}{ SV lớp TN } & \multicolumn{2}{|c|}{ SV lớp ĐC } & \multirow{2}{*}{$\begin{array}{c}\text { Khác biệt } \\
\bar{X} \\
\text { (Z) }\end{array}$} & \multirow{2}{*}{$\begin{array}{c}\text { Sig. } \\
\text { (2-tailed) }\end{array}$} \\
\hline & & $\overline{\mathbf{X}}$ & $S D$ & $\overline{\mathbf{X}}$ & $S D$ & & \\
\hline 1 & Hứng thú học tập môn học & 1,6550 &, 35615 & 2,3918 &, 50049 & ,73684 &, 000 \\
\hline 2 & $\begin{array}{l}\text { Khả năng độc lập và lưu giữ } \\
\text { kiến thức }\end{array}$ & 1,8596 & ,43910 & 2,3684 & ,43390 & ,50877 &, 000 \\
\hline 3 & Tính tự tin trong học tập & 2,2982 & ,48051 & 2,8640 & ,35061 & ,56579 &, 000 \\
\hline 4 & $\begin{array}{l}\text { Không khí tích cực trong lớp } \\
\text { học }\end{array}$ & 1,7135 &, 62817 & 2,4503 &, 55810 & ,73684 &, 000 \\
\hline 5 & $\begin{array}{l}\text { Kiến thức môn học và các kỹ } \\
\text { năng hành động }\end{array}$ & 1,7697 & ,48916 & 2,3860 & ,34010 & ,61623 &, 000 \\
\hline 6 & $\begin{array}{l}\text { Đầu tư thời gian cho ôn thi } \\
\text { hêt môn học }\end{array}$ & 1,8421 &, 56028 & 2,8246 & ,53861 & ,98246 &, 000 \\
\hline 7 & Điểm môn học đạt B+ & 1,8363 & ,41367 & 2,4152 & ,39981 & ,57895 &, 000 \\
\hline
\end{tabular}

trình và bài thi cuối kỳ chiếm trọng số $60 \%$ điểm môn học. Sinh viên sẽ tham gia đánh giá 02 bài tập chuyên đề cùng giáo viên (sinh viên tự đánh giá bài tập chuyên đề của mình kết hợp với sự đánh giá từ các bạn trong lớp và từ giảng viên phụ trách lớp).
Tính độc lập, tự tin và khả năng lưu giữ kiến thức của sinh viên cũng như không khí lớp học được cải thiện rất rõ qua mô hình HTKP. Sinh viên ngày càng chủ động hơn trong việc phát hiện và giải quyết các vấn đề về môn học, trong việc kiến tạo kiến thức cho mình với một trạng thái thoải mái, nhẹ nhàng 
và hầu như nắm được những vấn đề cơ bản ngay trên lớp học.

Đặc biệt thành quả mà sinh viên mong đợi nhất là kiến thức và các kỹ năng cũng như điểm số đánh giá môn học cũng đạt ở mức khá cao. Thực tế giải quyết các nhiệm vụ học tập, cùng với việc tự đánh giá và phản hồi của sinh viên sau mỗi giờ học cho thấy sinh viên học được nhiều kiến thức môn học, nhiều kỹ năng của họ được hình thành và phát triển hơn, như: kỹ năng tự học được nâng lên nhiều; kỹ năng phát hiện và giải quyết vấn đề thực tiễn được cải thiện; khả năng sáng tạo trong tiếp cận và tìm giải pháp cho vấn đề hay kỹ năng tổ chức hoạt động học tập, trình bày vấn đề được phát triển,...

Tuy nhiên, tính tự tin của sinh viên trong học tập so với các thành quả học tập khác mà sinh viên đạt được qua mô hình học tập khám phá là thấp hơn cả. Sự khác biệt này thể hiện qua thống kê khác biệt về trung bình, với mức ý nghĩa kiểm định $\mathrm{t}: 0,00<\mathrm{Sig}$. (hệ số ý nghĩa) $<0,002<\alpha=0.05$ (bảng $1 \& 2$ ). Trừ hứng thú học tập của sinh viên với môn học đạt được hiệu quả hơn một chút so với khả năng độc lập và lưu giữ kiến thức của sinh viên qua mô hình học tập khám phá, hiệu quả học tập đạt được của sinh viên ở những khía cạnh còn lại đều đạt ở mức ngang nhau. Kết quả này đã được kiểm chứng bằng Paired Samples T-Test (bảng 2).

Quan sát và trao đổi với sinh viên cho thấy tính tự tin, tự chủ của sinh viên trong học tập môn Giáo dục học qua mô hình học tập khám phá vẫn chỉ ở mức trung bình khá. Bởi với các môn học lý thuyết từ năm thứ nhất, sinh viên quen với việc nghe, ghi chép những kiến thức mà giảng viên giảng trên lớp và họ có tâm lý lo sợ những kiến thức mà họ tự xây dựng, tự tìm kiếm thông qua tương tác với bạn học không đủ chính xác, tin cậy như những kiến thức mà họ được nghe và ghi chép được qua lời giảng của giảng viên trên lớp. Hơn nữa, để kiến tạo cho bản thân kiến thức môn học này một cách hiệu quả, sinh viên cần có những kiến thức nền tảng về triết học, sinh lý học và tâm lý học. Đây là những môn học mà sinh viên đã được học từ năm thứ nhất và thứ hai. Tuy nhiên, phần lớn sinh viên cho biết họ đã quên khá nhiều kiến thức của các môn học này nên trong quá trình khám phá, kiến tạo kiến thức môn Giáo dục học họ không tự chủ và tự tin.

- Hiệu quả học tập đạt được của sinh viên qua các mô hình và PP hoc tập truyền thống

Sinh viên học môn Giáo dục học ở lớp sử dụng các phương pháp và mô hình học tập truyền thống là chủ yếu có hiệu quả học tập môn học ở mức trung bình khá, trong đó tính tự tin trong học tập môn học chỉ đạt ở mức dưới trung bình $($ Mean $\approx 2,9>2.5$ ) và thời gian mà sinh viên dành cho việc ôn tập môn học trước khi thi là không ít với Mean $\approx 2,8>2.5$. 
Bảng 2. Sự khác biệt về mức độ đạt được trong thành quả học tập của sinh viên có sự khác biệt trong mức độ đạt được so với những thành quả học tập khác mà sinh viên

\begin{tabular}{|c|c|c|c|c|c|}
\hline \multirow[b]{2}{*}{ STT } & \multirow[b]{2}{*}{$\begin{array}{l}\text { Hiệu quả học tập sinh viên đạt được sau } \\
\text { khi kết thúc môn học }\end{array}$} & \multicolumn{2}{|c|}{ SV lớp TN } & \multicolumn{2}{|c|}{ SV lớp ĐC } \\
\hline & & $\begin{array}{c}\text { Khác biệt TB } \\
\overline{\mathbf{X}}\end{array}$ & Sig. $(\alpha)$ & $\begin{array}{c}\text { Khác biệt TB } \\
\overline{\mathbf{X}}\end{array}$ & Sig. $(\alpha)$ \\
\hline 1 & $\begin{array}{l}\text { Hứng thú học tập } \\
\qquad- \text { Khả năng độc lập \& nhó }\end{array}$ &,- 19130 & ,001 & ,02339 & ,777 \\
\hline 2 & $\begin{array}{l}\text { Hứng thú học tập } \\
- \text { Tính tư tin trong hoc tập }\end{array}$ &,- 55652 & ,000 &,- 47222 &, 000 \\
\hline 3 & Hứng thú học tập - Không khí lớp học &,- 01739 & ,783 &,- 05848 & ,491 \\
\hline 4 & $\begin{array}{l}\text { Hứng thú học tập } \\
- \text { - Kiến thức \& kỹ năng }\end{array}$ &,- 13152 & ,015 & ,00585 & ,932 \\
\hline 5 & $\begin{array}{l}\text { Hứng thú học tập } \\
- \text { - Đầu tu thời gian ôn thi }\end{array}$ &,- 11304 &, 107 &,- 43275 & ,000 \\
\hline 6 & Hứng thú học tập - Điểm môn học &,- 10725 & 035 &,- 02339 & ,765 \\
\hline 7 & $\begin{array}{l}\text { Khả năng độc lập \& nhớ kiến thức } \\
- \text { Tính tự tin trong học tập }\end{array}$ &,- 36522 & ,000 &,- 49561 & ,000 \\
\hline 8 & $\begin{array}{r}\text { Khả năng độc lập \& nhớ kiến thức } \\
- \text { Không khi lớp học }\end{array}$ & , 17391 &, 002 &,- 08187 & ,262 \\
\hline 9 & $\begin{array}{r}\text { Khả năng độc lập \& nhớ kiến thức } \\
- \text { - Kiến thức \& kỹ năng }\end{array}$ & 05978 &, 113 &,- 01754 &, 739 \\
\hline 10 & $\begin{array}{l}\text { Khả năng độc lập \& nhớ kiến thức } \\
- \text { Đầu tur thời gian ôn thi }\end{array}$ & ,07826 & ,266 &,- 45614 &, 000 \\
\hline 11 & $\begin{array}{l}\text { Khả năng độc lập \& nhớ kiến thức } \\
\text { - Điểm môn học }\end{array}$ & ,08406 &, 061 &,- 04678 &, 523 \\
\hline 12 & $\begin{array}{l}\text { Tính tự tin trong học tập } \\
- \text { Không khi lớp học }\end{array}$ &, 53913 &, 000 & ,41374 &, 000 \\
\hline 13 & $\begin{array}{l}\text { Tính tự tin trong học tập } \\
\qquad \begin{array}{l}- \text { Kiến thức \& kỹ năng } \\
\end{array}\end{array}$ & ,42500 &, 000 & ,47807 &, 000 \\
\hline 14 & $\begin{array}{l}\text { Tính tự tin trong học tập } \\
- \text { Đầu tu thời gian ôn thi }\end{array}$ & ,44348 &, 000 & ,03947 &, 631 \\
\hline 15 & $\begin{array}{l}\text { Tính tự tin trong học tập } \\
\text { - Điểm môn học }\end{array}$ & ,44928 &, 000 & ,44883 &, 000 \\
\hline 16 & $\begin{array}{l}\text { Không khí lớp học } \\
\qquad \text { - Kiến thức \& kỹ năng }\end{array}$ &,- 11413 &, 064 & ,06433 & ,365 \\
\hline 17 & $\begin{array}{l}\text { Không khí lớp học } \\
\quad-\text { Đầu tu thời gian ôn thi }\end{array}$ &,- 09565 & ,244 &,- 37427 &, 000 \\
\hline 18 & Không khí lớp học - Điểm môn học &,- 08986 &, 129 &, 03509 & ,666 \\
\hline 19 & 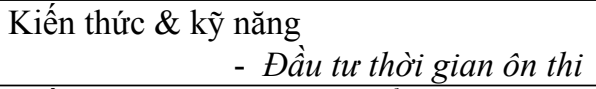 & ,01848 & ,794 &,- 43860 &, 000 \\
\hline 20 & Kiến thức \& kỹ năng - Điểm môn học &, 02428 & 483 &,- 02924 & 475 \\
\hline 21 & Đầu tư thời gian - Điểm môn học & ,00580 & ,931 & ,40936 &, 000 \\
\hline
\end{tabular}

Các khía cạnh khác mà sinh viên đạt được sau khi kết thúc môn học đều có điểm trung bình khoảng 2,4 - 2,5. Những thành quả mà sinh viên đạt được sau khi học tập môn học không có sự khác biệt nhiều về mức độ, chỉ có tính tự tin trong học tập môn học và thời gian mà sinh viên dành cho việc ôn tập môn học là đạt được (hứng thú học tập môn học; khả năng độc lập \& lưu giữ kiến thức; kiến thức \& các kỹ năng hành động; điểm môn học (bảng 2).

Kinh nghiệm giảng dạy môn học cũng như quan sát, trao đổi trực tiếp với giảng viên và sinh viên cho thấy: với cách lên lớp truyền 
thống của giảng viên khi giảng dạy các môn lý thuyết cho sinh viên thường tạo tâm lý mệt mỏi, không khơi dạy được ở sinh viên sự hứng thú cũng như sự tích cực của sinh viên trong giờ học. Phần nhiều sinh viên cố gắng ngồi nghe và ghi chép lại được một số thông tin, kiến thức từ giảng viên mà thiếu sự chủ động và hiểu hết những kiến thức và thông tin đó.

- Sư khác biệt về hiệu quả học tập đạt được của sinh viên ở hai nhóm $T N \&$ \&C

So sánh hiệu quả học tập đạt được của sinh viên ở nhóm lớp TN (lớp HTKP) \& ĐC (lớp học tập truyền thống) thì thấy có sự khác biệt rất rõ. Khác biệt thể hiện ở tất cả các khía cạnh mà sinh viên hai nhóm đạt được sau khi kêt thúc môn học: từ hứng thú học tập; tính độc lập, tự tin và khả năng lưu giữ kiến thức của sinh viên đến kiến thức, kỹ năng cũng như điểm số đánh giá môn học của sinh viên ở lớp có sử dụng mô hình HTKP cao hơn, trộihơn so những thành quả này của sinh viên ở lớp được học theo mô hình và PPDH truyền thống. Sự khác biệt này thể hiện qua thống kê khác biệt về trung bình, với hệ số ý nghĩa (Sig.) của kiểm định $\mathrm{t}=0,00<\alpha$ (mức ý nghĩa $=0.05$ ). (Kết quả thể hiện ở bảng 1).
4.3. Mối quan hệ giữa các khía cạnh về hiệu quả hoc tập đạt được của sinh vien qua mô hình hoc tập khám phá

Để khẳng định mối quan hệ giữa các khía cạnh đạt được trong học tập môn học của sinh viên và mối quan hệ của các khía cạnh này với sự thành thạo trong việc vận dụng mô hình học tập khám phá, chúng tôi đã sử dụng hệ số tương quan Pearson (ký hiệu r) để lượng hóa mức độ chặt chẽ của mối liên hệ tuyến tính giữa hai biến định lượng, $\mathrm{r}$ có giá trị nằm trong đoạn $[-1,1]$, giá trị tuyệt đối của $r$ cho biết mức độ chặt chẽ của mối liên hệ tuyến tính.

Kết quả cho thấy hầu hết các khía cạnh đạt được trong học tập môn học của sinh viên có mối quan hệ với nhau, ngoại trừ tính tự tin trong học tập của sinh viên với không khí lớp học và điểm môn học là không có mối quan hệ tuyến tính với nhau.

Đặc biệt, kiến thức môn học và các kỹ năng hoạt động mà sinh viên đạt được có mối quan hệ rất chặt chẽ với điểm môn học của sinh viên $(\mathrm{r}=0.73)$. Đây là một minh chứng thể hiện rất rõ tính logic và tính khoa học của nghiên cứu.

Bảng 3. Sự tương quan giữa các khía cạnh về hiệu quả học tập đạt được của sinh viên qua mô hình học tập khám phá

\begin{tabular}{|c|c|c|c|c|c|c|c|c|}
\hline & $\begin{array}{c}\text { HÚNG } \\
\text { THÚ }\end{array}$ & $\begin{array}{l}\text { ĐỘC LÂP } \\
\text { \& NHỚ }\end{array}$ & \begin{tabular}{|c|} 
TÍNH \\
TƯ TIN
\end{tabular} & $\begin{array}{l}\text { KHÔNG } \\
\text { KHÍ LÓPP }\end{array}$ & $\begin{array}{l}\text { KIẾN THỨC } \\
\& \text { KỸ NĂNG }\end{array}$ & $\begin{array}{c}\text { ĐIỂM } \\
\text { MÔN HỌC }\end{array}$ & \begin{tabular}{|l|} 
THÀNH \\
THẠO
\end{tabular} & $\begin{array}{c}\text { HIÊU QUẢ } \\
\text { MỐ HİNH }\end{array}$ \\
\hline $\begin{array}{l}\text { Hứng thú học } \\
\text { tập môn học }\end{array}$ & 1 &, $197^{*}$ &, $305^{* *}$ & ,206 &, $327^{k *}$ &, $261^{\text {** }}$ & , 140 & ,225 \\
\hline $\begin{array}{l}\text { Khả năng độc } \\
\text { lập và lưu giữ } \\
\text { kiến thức }\end{array}$ & & 1 &, $234^{*}$ &, $427^{* *}$ &, $683^{* *}$ &, $454^{* *}$ &, $425^{* *}$ &, $514^{* *}$ \\
\hline $\begin{array}{c}\text { Tính tự tin trong } \\
\text { học tập }\end{array}$ & & & 1 & 116 &, $275^{\text {** }}$ & ,006 &, $280^{* *}$ &, $377^{* *}$ \\
\hline $\begin{array}{l}\text { Không khí tích } \\
\text { cực trong lớp học }\end{array}$ & & & & 1 &, $347^{* *}$ &, $321^{* *}$ &, $378^{* * *}$ &, $451^{* *}$ \\
\hline $\begin{array}{l}\text { Kiến thức môn } \\
\text { học và các kỹ } \\
\text { năng hành động }\end{array}$ & & & & & 1 &, $726^{* *}$ &, $369^{* *}$ &, $592^{* *}$ \\
\hline $\begin{array}{c}\text { Điểm môn học } \\
\text { đạt B+ }\end{array}$ & & & & & & 1 &, $246^{* *}$ &, $400^{* *}$ \\
\hline $\begin{array}{c}\text { Thành thạo mô } \\
\text { hình HTKP }\end{array}$ & & & & & & & 1 &, $371^{* *}$ \\
\hline $\begin{array}{c}\text { Hiệu quả của mô } \\
\text { hình HTKP }\end{array}$ & & & & & & & & 1 \\
\hline
\end{tabular}


*. Correlation is significant at the 0.05 level (2-tailed).

**. Correlation is significant at the 0.01 level (2-tailed).

Hiệu quả học tập đạt được của sinh viên có mối quan hệ khá chặt với sự thành thạo vận dụng mô hình học tập này trong dạy học môn học của giảng viên (hệ số tương quan $\mathrm{r} \approx 0.4$ ). Điều này cho thấy sự thành công của mô hình học tập khám phá phụ thuộc khá nhiều vào khả năng vận dụng mô hình học tập này của giảng viên, vào sự đầu tư, chuẩn bị cũng như kiến thức của giảng viên.

\section{Kết luận}

Học tập khám phá là quá trình học tập tích cực, giúp người học phát triển các kỹ năng hành động với mức độ độc lập và tự chủ cao của cá nhân người học. Mô hình học tập này mang lại hiệu quả học tập cao hơn và vượt trội hơn cho người học so với các phương pháp và mô hình học tập truyền thống. Việc vận dụng mô hình học tập khám phá trong giảng dạy môn giáo dục học - môn đào tạo nghề sư phạm ở Trường ĐHNN - ĐHQGHN đã mang lại những thành quả học tập đáng kể cho sinh viên. Do vậy, giảng viên nên vận dụng mô hình học tập này thường xuyên trong giảng dạy các môn nghiệp vụ sư phạm ở Trường ĐHNN - ĐHQGHN nói riêng và các môn học ở bậc giáo dục đại học nói chung để góp phần tạo ra những sản phẩm giáo dục đáp ứng yêu cầu của xã hội đặt ra.

\section{Tài liệu tham khảo}

\section{Tiếng Việt}

Nguyễn Hữu Châu, Cao Thị Hà (2004). Cơ sở lí luận của lí thuyết kiến tạo trong dạy học. Tạp chi Thông tin Khoa học giáo duc, số 103/2004, tr 1-4.

Nguyễn Phúc Chỉnh, Nguyễn Thị Hằng (2010). Dạy kiến thức quá trình sinh học ở cấp độ phân tử (sinh học 12) theo quan điểm của thuyết kiến tạo. Tạp chí Giáo ducc, Số 236 (kỳ 2), tr 44.

Phó Đức Hoà (2012). Nghiên cứu học tập khám phá theo thuyết kiến tạo trong dạy học ở tiểu học. Báo cáo tổng kết đề tài nghiên cứu khoa học. Hà Nội: Trường Đại học Sư phạm Hà Nội.

Trần Bá Hoành (2004). Dạy học bằng các hoạt động khám phá có hướng dẫn. Tạp chí Thông tin khoa học giáo dục, số 102/2004, tr. 2-6.

Nguyễn Phú Lộc (2001). Học tập khám phá - một phương pháp dạy học nâng cao tính tích cực của học sinh trong dạy học toán. Tạp chí Giáo duce, số 19 $(12 / 2001)$.

Phan Trọng Ngọ (2005). Dạy hoc và phuơng pháp dạy hoc trong nhà truờng. Hà Nội: Nxb ĐHSP Hà Nội.

\section{Tiếng Anh}

Baker, E. A. (2000). Case-based learning theory: Implications for software design. Journal of Technology and Teacher Education. 8(2), 85-95.

Bicknell-Holmes, T. \& Hoffman, P. S. (2000). Elicit, engage, experience, explore: Discovery learning in library instruction. Reference Services Review. 28(4), 313-322.

Bonwell, C. C. (1998). Active Learning: Energizing the Classroom. Green Mountain Falls, CO: Active Learning Workshops.

Bruner, J. (1960). The Process of Education. Cambridge, MA: Harvard University Press.

Bruner, J. S. (1961). The act of discovery. Harvard Educational Review, 31, 21-32.

Chambers, D. W. (1971). Putting down the discovery learning hypothesis . Educational Technology. 11(3), 54-59.

J. Castronova (2002). Discovery learning for the $21 \mathrm{st}$ century: what is it and how does it compare to traditional learning in effectiveness in the $21 \mathrm{st}$ century. Literature Reviews, Action Research Exchange 1, no. 2, 2002.

Cohen, Marisa T. (2008). The Effect of Direct Instruction versus Discovery Learning on the Understanding of Science Lessons by Second Grade Students. NER Conference Proceedings 2008. 30.

Laelatul Mukharomah (2015). The Use of Discovery Learning Model to Improve Students' Descriptive Text Writing. Thesis, Semarang: Bachelor Program of English Language Education of Tarbiyah Faculty of Walisongo State Islamic University Semarang, 2015.

Lewis, Rachel(2006). Discoverylearning in mathematics education: Using multimedia technology to reach teachers. Thesis. Master's Project. Rochester Institute of Technology.

Mabie, R. \& Baker, M. (1996). A comparison of experiential instructional strategies upon the science process skills of urban elementary students. Journal of Agricultural Education. 37(2), 1-7.

Marilla D. Svinicki (1998). A Theoretical Foundation for Discovery Learning. Advances in Physiology Education. 20 (1), December.

Monireh Eskandari \& Hassan Soleimani (2016). The Effect of Collaborative Discovery Learning Using 
MOODLE on the Learning of Conditional Sentences by Iranian EFL Learners. Theory and Practice in Language Studies, 6 (1), 153-163.

Oghenevwede, O. E. (2010). Effects of Discovery and Inquiry Approches in Teaching and Learning of Biology on Secondary School Students' Performance In Delta State, Nigeria. Journal of Research in Education and Society, 1 (1), April 2010.

Saab, N., Van Joolingen, W. R., \& Van Hout-Wolters, B. H. A. M. (2005). Communication in collaborative discovery learning. British Journal of Educational Psychology, 75, 603-621.

Van Joolingen, W. (1998). Cognitive tools for discovery learning. International Journal of Artificial Intelligence in Education, 10, 385-397.
Veermans, K. H. (2003). Intelligent support for discovery learning. Doctoral dissertation, Netherlands Twente University Press.

William Mirasi, Joseph Osodo and Israel Kibirige (2013). Comparing Guided Discovery and Exposition-with-Interaction Methods In Teaching Biology in Secondary Schools. Mediterranean Journal of Social Sciences. MCSER Publishing, Rome-Italy, 4 (14), November 2013.

Yunisa Rahmi and Ratmanida (2014). The Use of Discovery Learning Strategy in Teaching Reading Report Texts To Senior High School Students. JELT, 3 (1), Serie C. $9 / 2014$.

\title{
EFFECTS OF DISCOVERY LEARNING ON TEACHING AND LEARNING PEDAGOGICAL SUBJECTS TO MEET OUTCOME STANDARDS AT UNIVERSITY OF LANGUAGES AND INTERNATIONAL STUDIES, VNU
}

\author{
Nguyen Thi Thang \\ Division of Educational Psychology, VNU University of Languages and International Studies, \\ Pham Van Dong, Cau Giay, Hanoi, Vietnam
}

\begin{abstract}
Based on the description of essential aspects of discovery learning, the study focuses on the effects of discovery learning in comparison with traditional approaches in teaching and learning pedagogy, one of the pedagogical subjects at the University of Languages and International Studies, Vietnam National University, Hanoi. With quantitative and qualitative methods, including two main research methods: pedagogical experiments and questionnaire, the study results show that discovery learning is much more effective than traditional approaches in teaching and learning pedagogy, as seen in the following aspects: learning motivation; independence and retention; self-confidence and autonomy in the learning process; academic knowledge, professional skills and action skills; a positive learning environment; less learning time but higher scores. As a result, it is recommended that discovery learning should be applied more often in teaching and learning pedagogical subjects as well as other subjects at tertiary level.

Keywords: discovery learning, teaching and learning, methods, efficiency, pedagogical subjects
\end{abstract}

